2 Jellie HG, Gonder JR, Canny CLB, Arce FP, Kaufmann JC. Ocular involvement in thrombotic thrombocytopenic purpura; the angiographic and histopathological features. Can J Ophthalmol 1984; 19: 279-283.

3 Power MH, Regillo MC, Custis PH. Thrombotic thrombocytopenic purpura associated with purtscher retinopathy. Arch Ophthalmol 1997; 115(1): 128-129.

4 Patel MR, Bains AK, O'Hara JP, Kallab AM, Marcus DM. Purtscher retinopathy as the initial sign of thrombotic thrombocytopenic purpura/hemolytic uremic syndrome. Arch Ophthalmol 2001; 119(9): 1388-1389.

T Ong, W Nolan and J Jagger

Ophthalmology Department, Royal Free Hospital London NW3, UK

Correspondence: T Ong

Tel: + 447760273918

Fax: + 442086929111

E-mail: tuyen.ong@doctors.org.uk

Eye (2005) 19, 359-361. doi:10.1038/sj.eye.6701491

Published online 1 October 2004

Sir,

\section{Calcification of Aqua-Sense intraocular lenses}

We read with interest the article by Izak and co-workers, reporting clinical and pathological features of hydrophilic acrylic intraocular lenses (IOLs) of three major designs explanted because of late postoperative opacification. ${ }^{1}$

These authors analysed eight Aqua-Sense IOLs (Ophthalmic Innovations International, OII). Five of them had been explanted in South Africa, two in the UK, and one in Brazil. According to the paper, a total of 23 cases of postoperative opacification of the Aqua-Sense lenses were observed by Dr Troskie in South Africa, and the manufacturer of the Aqua-Sense lens has apparently reported 12 similar cases to the authors in a personal communication in September 2001. ${ }^{1}$

In the University Hospital Aintree, Liverpool, UK, we have exchanged 25 opacified Aqua-Sense lenses between August 2001 and July 2003. The initial Aqua-Sense IOL implantations were performed in the year 2000 and early 2001. We summarised our experience with the exchange of these lenses in a paper that we submitted recently for consideration of publication in the Journal of Cataract and Refractive Surgery.
A further nine Aqua-Sense lenses developed severe late opacification but have not been exchanged so far for various reasons, bringing the total number of opacified Aqua-Sense lenses observed in our department to 34 . Thus, the overall number of opacified Aqua-Sense lenses might be higher than suggested in the article and we are wondering whether other colleagues have exchanged or observed opacified Aqua-Sense lenses.

\section{Acknowledgements}

Proprietary interests: Research funding: none.

\section{References}

1 Izak AM, Werner L, Pandey SK, Apple DJ. Calcification of modern foldable hydrogel intraocular lens designs. Eye 2003; 17: 393-406.

E Dagres, MA Khan, GM Kyle and D Clark

Department of Ophthalmology, University Hospital

Aintree, Liverpool, UK

Correspondence: E Dagres

Tel: + 447811405836

Fax: + 441515294283

E-mail: edagres@yahoo.com

Eye (2005) 19, 361. doi:10.1038/sj.eye.6701502

Published online 30 July 2004

Sir,

Bilateral, multiple choroidal effusions after vomiting

Choroidal effusions occur secondary to local changes such as hypotony, surgery, or inflammation. Primary uveal effusion may also occur with nanophthalmos or scleral abnormalities. ${ }^{1}$ Acute choroidal effusion has been described in association with local or systemic predisposing factors. ${ }^{2-6}$ We present a patient with acute, bilateral choroidal effusions related to an episode of vomiting alone.

A 64-year-old man presented with a 2-day history of painless visual loss in the left eye noticed the morning after an episode of vomiting. Other than type II diabetes mellitus, his past medical and ocular histories were unremarkable. Visual acuity with low myopic correction was 6/6 in the right eye and 6/36 in the left. Examination of the ocular adnexae, anterior segments, and intraocular pressure was normal. Dilated fundal examination revealed multiple, shallow choroidal effusions in the 


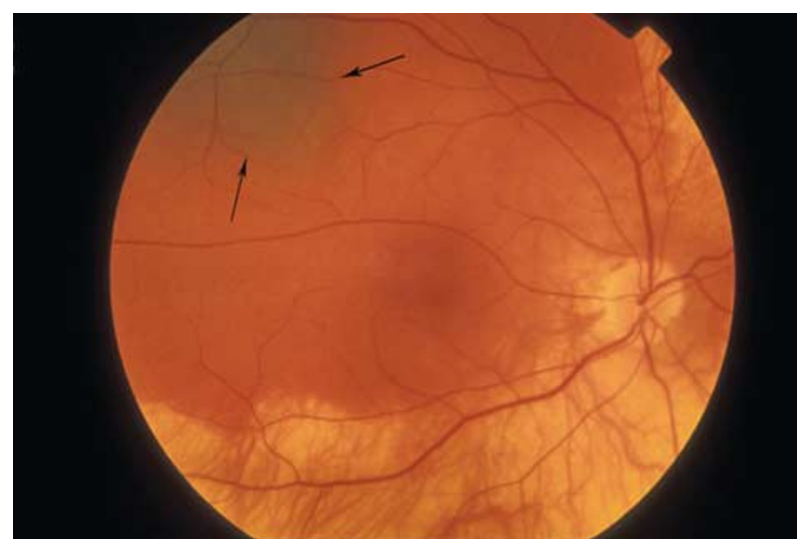

Figure 1 Small choroidal effusion affecting the posterior pole of the right eye.

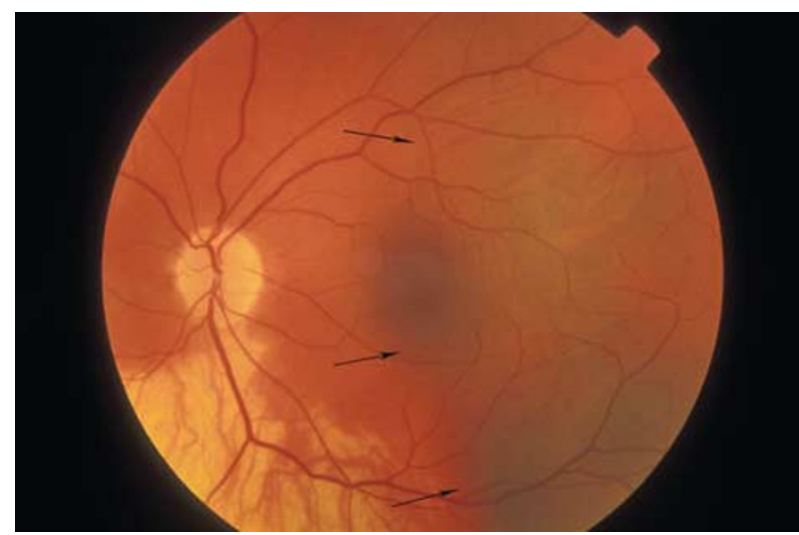

Figure 2 Larger choroidal effusions seen at the posterior pole of the more symptomatic left eye.

posterior pole and anterior to the equator of both eyes (Figures 1 and 2), involving the fovea in the left. There was no vitritis, retinitis, or vasculitis. B-mode ultrasonography confirmed shallow choroidal detachments with low internal reflectivity and no scleral thickening. Axial lengths (measured at presentation) were within normal limits $(24 \mathrm{~mm})$. A CT scan of the globes, fluorescein and indocyanine green angiography were unremarkable. Without treatment, his visual symptoms and signs resolved over 2 months and his corrected acuity returned to $6 / 6$.

Acute choroidal detachments secondary to haemorrhage or effusion have been described previously. Many of these patients had known risk factors including impaired episcleral venous outflow, topical glaucoma therapy, prior ocular surgery, high myopia, or systemic anticoagulation. ${ }^{2-6}$ To our knowledge, there are only two published reports of acute choroidal detachment precipitated by Valsalva manoeuvre without other risk factors. Hammam and Madhavan ${ }^{7}$ described an acute rise in intraocular pressure following unilateral choroidal haemorrhage precipitated by straining during a bowel movement. Suan et $a l^{8}$ reported bilateral choroidal effusions occurring 3 days after prolonged vomiting. In our patient, lack of pain, low internal reflectivity, and the multifocal, bilateral nature point towards this being choroidal effusion rather than haemorrhage. Choroidal effusion can occur due to reduced trans-scleral movement of fluid, which may be secondary to scleral abnormality or, as in this case after Valsalva manoeuvre, raised intrathoracic pressure can increase back pressure in the venous drainage system.

\section{References}

1 Uyama M, Takahashi K, Koraki J, Tagami N, Takada Y, Okhuma $\mathrm{H}$ et al. Uveal effusion syndrome. Ophthalmology 2000; 107(3): 441-449.

2 Akduman L, Del Priore LV, Kaplan HJ, Meredith T. Uveal effusion symdrome associated with primary pulmonary hypertension and vomiting. Am J Ophthalmol 1996; 121(5): 578-580.

3 Mazzeo V, Galli G, Signori D, Perri P. Spontaneous choroidal detachment and red-eyed shunt syndrome: two clinical entities with the same cause? Int Ophthalmol 1985; 8(3): 129-138.

4 Davani S, Delbosc B, Royer B, Kantelip J-P. Choroidal detachment induced by dorzolamide 20 years after cataract surgery. Br J Ophthalmol 2002; 86: 1457-1458.

5 Chak M, Williamson TH. Spontaneous suprachoroidal haemorrhage associated with high myopia and aspirin. Eye 2003; 17: 525-527.

6 Manuchehri K, Loo A, Ramachandani M, Kirby GR. Acute suprachoroidal haemorrhage in a patient treated with streptokinase for myocardial infarction. Eye 1999; 13(3): 685-686.

7 Hammam T, Madhavan C. Spontaneous suprachoroidal haemorrhage following a valsalva manoeuvre. Eye 2003; 17: 261-262.

8 Suan EP, Rubsamen PE, Byrne SF. Bilateral ciliochoroidal detachments after Valsalva maneuver. Arch Ophthalmol 1993; 111: 304 .

\section{FM Cuthbertson and M McKibbin}

Department of Ophthalmology

St James's University Hospital

Beckett Street

Leeds LS9 7TF, UK

Correspondence: F Cuthbertson

Tel: +441132066429

Email: fcuthbertson@hotmail.com

Eye (2005) 19, 361-362. doi:10.1038/sj.eye.6701500

Published online 30 July 2004 